\title{
COPIM
}

\section{Community Governance Explored}

\section{Sam Moore, Janneke Adema}

Published on: Apr 27, 2020

DOI: $10.21428 / 785 a 6451.20 a 5 c 646$

License: Creative Commons Attribution 4.0 International License (CC-BY 4.0). 
As part of our research on governance for the COPIM project, we (Sam and Janneke) are currently undertaking a landscape analysis, initially based on desk research. For this analysis we are looking at the kinds of organisational structures different projects and institutions in the scholarly communication and publishing space (ones that focus on open access publishing and open infrastructure, or whose mission is close to COPIM's), use to govern their efforts. By examining the disparate approaches to and best practices around governance that are being employed in scholarly communication, we hope to understand how best to devise our own horizontal governance systems for the infrastructures and workflows COPIM is currently developing to support open access for books. In the next stage of our research, we will continue our exploration by additionally looking at various grassroots and activist organisations outside the scholarly communication space that are engaged in experiments with community governance that might be of interest to COPIM. We hope this will help inform our project in creating the durable organisational structures that we need for the coordination, governance and administrative support of the project's community-owned infrastructure.

But what actually is governance and how is it currently used in the scholarly communication space? Although our research is still ongoing we would like to share some first reflections and observations.

\section{Formal vs Informal}

The commons researcher Elinor Ostrom theorised that good governance requires rules and community trust within a social setting. This means that for her, governance is both social and institutional, based on both rules and norms. When we think of governance, we might consider the formal systems covering rules, organisational structures, voting rights, constituents and hierarchies of power that are involved in managing an organisation. For example, as it states on their website, the Open Library of Humanities (one of the organisations we have had a look at) is registered as a charity in the UK and governed by its four trustees, each of which is a humanities academics from the UK. OLH has an organisational structure comprising an academic advisory board and a library board, next to the OLH directors and trustees. These entities collectively determine budget increases and vote on which journals to admit to the platform (with one library member receiving one vote). This system thus distributes decision making across a number of actors and ensures that all members have a stake in the publisher's future. And the OpenAIRE project, a European technical infrastructure and network promoting open science and providing open publishing services, consists of a partnership of more than 60 research institutions. As its website states, as a Greek legal entity OpenAIRE follows a participatory governance framework. Its current governance structure consists of three bodies: a General Assembly (its highest decision making body composed of OpenAIRE's members), an Executive Board (steering) and a Management Office (daily activities). It also has formal statutes that outline its governance procedures, which are regularly revised by the General Assembly. 
Yet many projects in the scholarly communication space do not have a defined - or at least observable - system of governance and governance procedures in place (clear roles, responsibilities) and instead rely on an advisory board structure as their primary method of accountability (i.e. a board that 'advises' and hence does not directly make decisions, although we are aware that in some instances advisory boards can be more involved in these kinds of processes). A 2019 study by Educopia found that $100 \%$ of the 33 scholarly communication resources they investigated were governed by a board or leadership group, showing that advisory boards are common in this space (p. 33). For example, the Collaborative Knowledge Foundation (Coko) is advised by a board of experts that meets regularly to 'help inform Coko's current and future directions.' Similarly, open access monograph publishers like

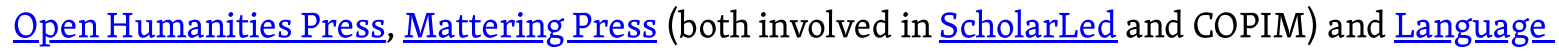

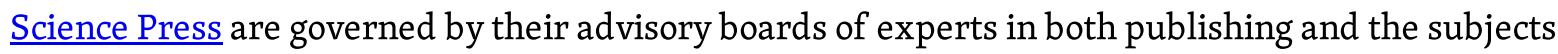
they publish. Open Humanities Press also operates a devolved editorial structure whereby individual editorial collectives ('thematic scholarly communities') are given autonomy to make editorial decisions, with books published centrally by the press under the Open Humanities Press imprint.

Though the advisory board structure (which is overall quite common in academia) may be a useful way of soliciting expert advice and guidance in an organisation, it is a difficult governance model to draw lessons from because its actual functioning and procedures often remain quite opaque. Many of the organisations we researched that employ an advisory board model do so without any public information on how the advisory board steers and interacts with the organisation at large. The question is whether this means that such information does not exist or if organisations have deliberately elected to not make this kind of information related to their governance publicly available for example in the form of formal bylaws, statutes or policies. Whether 'informality' here is a specific choice, an example of organisations simply following common practice around minimal governance, a sign of inexperience, or simply a not fully developed governance structure remains unclear from our initial research, but we will come back to this in a bit.

\section{Scale}

One of the overarching philosophies the COPIM project works with is that of 'scaling small', where through establishing strong relationships between existing independent organisations, as well as sharing open source tools, infrastructures, resources, skills, and best practices amongst each other in a non-competitive environment, these organisations can together grow stronger and scale both horizontally and vertically whilst becoming more resilient and retaining their independence. This is what we have been doing through organisations such as $\underline{\text { ScholarLed }}$ and the Radical Open Access Collective (ROAC), and we now hope to 'scale' this even further through the services, infrastructures and platforms provided through COPIM. But how would this 'scaling small' continue to work best when 
an organisation grows in members (scaling horizontally) and establishes increasingly more relationships with other partners in scholarly communication (scaling vertically)?

It is interesting to see how some other large membership organisations have been dealing with these issues in relation to governance. SciELO, conceived in 1996 to address the issue that most Latin American journals lacked international indexing, aims to increase the visibility of national journals in the region, which are mostly managed and produced independently by scholarly communities (i.e. not by commercial publishers). As such, SciELO operates as a decentralised network and a cooperative electronic publishing model of open access journals. It provides a model or road map for national SciELO collections to operate; however, the governance, management and funding of the SciELO collections is mostly done through national research agencies. One of the national collections, SciELO Brazil, acts as the network technical secretariat and provides on-going maintenance of the methodological and technological platform. On the other hand, CLACSO, the largest academic network in Latin America and the Caribbean bringing together more than 600 research and postgraduate institutions from 51 countries, operates a more centralised form of governance. Its day to day operations are carried out by a Secretariat in Buenos Aires, led by the Executive Secretary, where the Secretariat responds to a Steering Committee - the Comite Directivo - comprised of members representing the distinct sub-regions within the network. The General Assembly, then is, in turn, comprised of representatives of all member institutions and meets every two and a half to three years.

Yet what is so inspirational about these non-commercial academic publishing platforms operating in Latin America, is that through their shared mission around community-led and owned scholarly communication, based on non-profit models and open access to publications, these platforms also scale vertically, supporting each other and closely working together. For example, CLACSO, Redalyc (the Network of Scientific Journals from Latin America and the Caribbean, Spain and Portugal) and AmeliCA (a cooperative infrastructure for scientific communication for Latin America's and the Global South's journals) are directly collaborating, following 'efforts conceived in the South and for the South'. Redalyc and AmeliCA are prime examples of scholar-led organisations. Redalyc began as an academic project of the Universidad Autónoma del Estado de México (Autonomous University of the State of Mexico) under the responsibility of the Research Group Science Communication and Dissemination, and is managed by a Board of Directors consisting of scholars whilst being overseen by a scientific advisory committee. AmeliCA is led by both Redalyc and CLACSO (with support from UNESCO) and is the outcome of a strategic relationships between these platforms as a response to the specific challenges of delivering open access that are faced by countries in Latin America and the Global South. Thinking through how these forms of vertical strategic alliances between networks, organisations and platforms might also again be translated in forms of shared governance between them, will be important for COPIM. 


\section{Mission}

Even though we have discussed different forms of more formal and informal governance, and how scale and collaboration might further influence governance models, we want to come back to how perhaps in some cases 'good governance' involves less formalised, centralised, hierarchical or expansive structures, rules and procedures, especially when we consider some of the smaller scholarled and not-for-profit entities that we are also researching for our study. Their scale, organisational structure, and mission might ask for or require a different approach to governance, for example one that from the start takes into consideration an organisation's mission, values, philosophy and the community it serves, all of which feed into the social norms that determine how a project is governed. This is where governance, we would argue, starts to take on an interesting dimension in scholarly communication, showing the importance of a mission to how a project operates.

Within the Radical Open Access Collective (which we co-organise), for instance, we have been discussing an informal and horizontal approach to governance based on the concept of 'lazy consensus'. Originating in open source communities, the lazy consensus approach to governance is mostly reactive and requires members to propose an action that will be passed if no one objects within a certain time frame (72 hours for example). If members do object, then discussion continuous until a solution is reached. Lazy consensus, for the ROAC, is something we are exploring in recognition of our horizontality and informality, presupposing that few decisions will actually need to be made, and when they are, that the discussion will be relatively consensual. Perhaps such a model would be less suitable It would not work for organisations who need to make regular decisions that impact other projects, nor would it perhaps be workable for active communities who regularly disagree with one another (as stuff wouldn't get done!).

Following Ostrom's general approach, we can assert that governance is situated, which is to say it depends on the kind of organisation, network, project or infrastructure being governed, the community governing it and the scale of its operations. Mission statements are critical to understanding this situatedness. For example, the ScholarLed consortium's mission statement reads as follows:

The aim of the collective is to explore the potential of working together. This includes developing systems and practices that allow presses to provide each other with forms of mutual support, ranging from pooled expertise to shared on- and offline infrastructures. Members of the consortium each retain their distinct identity as publishers, with different audiences, processes, business models and stances towards Open Access. What they share, however, is a commitment to opening up scholarly research to diverse readerships, to resisting the marketization of academic knowledge production, and to working collaboratively rather than in competition. 
Similarly, the Radical Open Access Collective goes into detail about its philosophy, including its commitment to openness, experimentation, ethics of care, and critiques of the status quo. A commitment to care is also displayed by Mattering Press, particularly in the blog posts and presentations by its organisers. Joe Deville describes how Mattering Press was founded in reaction to the 'instrumentalization' of scholarship and as a way to explore new approaches to care and relationality in publishing and beyond.

The Next Generation Libraries Project (NGLP)recent report Encouraging Adherence to Values and Principles in Scholarly_Publishing has made an important start here by analysing how specific (academic) values - such as openness and transparency - underlie and relate to the governance models of various scholarly publishing service providers. Through their analysis of 100 "values and principles" statements, the authors directly oppose academic values to the "profit motivations [that] have come to dominate the current scholarly publishing marketplace', for example by comparing 'mission-driven' and 'profit-driven' motivations. This report is essential reading for organisations that are interested in non-market approaches to governance and value.

The situatedness of an organisation therefore seems vital to consider when devising systems of governance, especially for the approach to horizontality and community governance we are exploring for COPIM. The COPIM project is somewhat unique in that it consists of multiple partners that themselves have different governance structures and values (see our list of member organisations here), not to mention the numerous libraries, publishers, scholarly societies and other stakeholders that forms its community to come, and which will contribute to the overall community-led governance models we are developing. For the work we are doing for COPIM, we are exploring how to design infrastructure, workflows and financial resilience to support open access monographs as well as ways to encourage their re-use and preservations in various versions and formats, all through open access business models and consortial arrangements (predominantly between scholar-led and not for profit publishers and libraries, but also involving other communities within the landscape of open access monograph publishing). Establishing who this community is we are supporting through our work whilst at the same time bringing this community about through our ongoing development, research, advocacy, and collaborations, is essential, as is exploring how best to involve this yet undefined and perhaps in some ways always contingent community in our governance structures. This will be the subject of some of our forthcoming blogposts.

Much like our initial exploratory work here, the NGLP report shows that there is a clear need to better understand the interplay between an organisation's mission, values, organisational model and its governance structures. We will continue to explore these issues with many of the organisations mentioned in this blogpost and hope to learn more from them as part of workshops we will be conducting in the near future. We will report back from these workshops soon! 